\title{
Quantificação e identificação de quirópteros soropositivos para Lyssavirus em publicações da base de dados da SciELO
}

\author{
[Quantification and identification of seropositive chiropters for Lyssavirus in publications of the \\ data base of SciELO]
}

\section{"Artigo Científico/Scientific Article"}

\author{
José Matheus Beltrami ${ }^{*}$, Marcelo Aparecido Marques, Grazielli de Fátima Serenini, Isabela \\ Carvalho dos Santos, Ricardo de Melo Germano, Daniela Dib Gonçalves, André Felipe Berto \\ Almada, Luciana Kazue Otutumi
}

Programa de Pós-Graduação em Ciência Animal com Ênfase em Produtos Bioativos, Unipar, Umuarama-PR, Brasil. *Autor para correspondência/Corresponding author: E-mail: mateus.beltrami@ hotmail.com

\begin{abstract}
Resumo
Lyssavirus apresenta grande importância na área da medicina humana e animal, este agente etiológico foi responsável por diversos surtos ao longo dos anos. Em grande parte dos casos, animais de vida silvestre também são afetados, um deles são os morcegos, quando feita uma relação deles com o vírus rábico é possível determinar não somente como a acontece a propagação do vírus mas também como ela afeta a vida deste animal. O método utilizado para a formulação deste trabalho foi o de bibliometria, a base de dados consultada foi a SciELO, posteriormente para determinar o assunto a ser pesquisado foram escolhidas as seguintes palavras-chave "morcegos e raiva" no período de 2007-2017. Dos 40 artigos encontrados houve a necessidade de delimitar a busca para trabalhos que apresentavam pesquisas envolvendo a captura de morcegos para posterior análise de positividade para o vírus da raiva. Das publicações encontradas 17 delas apresentavam os requisitos necessários para o desenvolvimento do presente trabalho. Observou-se que 18.248 morcegos foram capturados ao longo de 10 anos e destes apenas $504(2,76 \%)$ foram soropositivos para a doença, ressalta-se o fato que a maior parte das amostras foram provenientes de morcegos não hematófagos. De acordo com os resultados conclui-se que, ao contrário da crença popular, os morcegos não hematófagos estão diretamente ligados à transmissão do Lyssavirus, contudo ainda é necessário conduzir maiores investigações nesta área.
\end{abstract}

Palavras-chave: bibliometria; morcegos; raiva; vírus rábico.

\begin{abstract}
Lyssavirus is of great importance in the area of human and animal medicine, where this etiological agent has been responsible for several outbreaks over the years. In some cases, wild animals are also affected, including bats. The study of bats' relationship with the rabies virus can show not only how the virus spreads but also how it affects the life of this animal. This subject was reviewed using bibliometrics, and the database consulted was SciELO. The keywords "bats and rabies" were chosen for the period 2007-2017. Of the 40 articles found there was a need to narrow the search to studies that presented research involving the capture of bats for later analysis of positivity for the rabies virus. Of the articles found, 17 of them met the necessary requirements for inclusion in this work. A total of 18,248 bats were reported captured over 10 years; only $504(2.76 \%)$ were seropositive for the disease, and it is worth noting that most of the samples were from non-hematophagous bats. On the basis of the results, we conclude that, contrary to popular belief, non-hematophagous bats are directly linked to the transmission of Lyssavirus, but further investigations in this area necessary.
\end{abstract}

Keywords: bibliometry; bats; rabies; rabies virus. 


\section{Introdução}

Os vírus são parasitas intracelular obrigatórios que podem ser encontrados em qualquer ambiente da Terra, sendo formados por material genético de DNA ou RNA, mas que apesar de sua simplicidade apresenta relevância para saúde humana e animal (Flores, 2007). Isso se justifica pelo fato de serem responsáveis por uma ampla variedade de doenças tanto em regiões urbanas como rurais em todo o mundo, devido à sua alta capacidade de mutação o que os torna imunes a diversos medicamentos dificultando o tratamento de pessoas acometidas por doenças virais (Samson et al., 2013).

O vírus rábico pertence ao gênero Lyssavirus da família Rhabdoviridae (Johnson, 2010) e sua transmissão está relacionada ao contato dos animais domésticos com animais selvagens, por meio da saliva do animal infectado, pela mordida ou arranhão (Lima e Gagliani, 2014).

A raiva pode ocorrer de duas formas epidemiológicas diferentes, a raiva urbana, tendo os animais domésticos (cães e gatos) como reservatório do agente e a raiva silvestre, aqueles presentes nas espécies de mamíferos selvagens, sobretudo tendo os morcegos como reservatório (Núñez et al., 2012).

Os morcegos são animais que apresentam mais estreita relação com a manutenção desse patógeno em ambientes naturais (Wang e Cowled, 2015) tanto pela sua alta diversidade de hábitos alimentares, entre eles a hematofagia, bem como pela capacidade de voo, que durante migrações facilita a rápida disseminação do vírus para lugares distantes (Calisher et al., 2006). Também, o comportamento de formação de colônias, muitas vezes compostas por morcegos de espécies diferentes, aumenta as chances de infecção e favorece a manutenção do agente patogênico (Tiriba e Shmal, 2010).

O objetivo deste trabalho foi quantificar os morcegos soropositivos, em artigos científicos, para o vírus da raiva assim como identificar suas respectivas características em artigos presentes na base de dados da SciELO.

\section{Material e Métodos}

A metodologia adotada foi a bibliometria (Macias-Chapula, 1998; Vanti, 2002). A fonte dos artigos foi unicamente o banco de dados SciELO (www.scielo.org.br), que apresenta publicações advindas de diversos países responsáveis por publicações ibero-americanas, tais como
Argentina, Brasil, México, Chile, Portugal, entre outros.

A estratégia usada na pesquisa de dados foi feita a partir do uso das seguintes palavras-chave em português e inglês: "morcegos e raiva" e "bats and rabies". As mesmas foram submetidas à pesquisa sobre os parâmetros "regional" e "método integrado" a fim de determinar apenas o Brasil como fonte dos artigos assim como, também foi determinado o período de busca de 10 anos, compreendendo as publicações de 2007 a 2017 sem distinções em relação ao idioma em que o trabalho foi escrito.

Posteriormente foi delimitada a busca de forma a considerar apenas os artigos que apresentavam pesquisas envolvendo de alguma forma a captura de morcegos, a fim de avaliar a positividade do vírus da raiva em quaisquer tecidos que foram previamente descritos de acordo com os métodos de análise apresentados. Dos 40 artigos encontrados, foram desconsiderados aqueles que não apresentaram o número de morcegos que foram submetidos aos testes laboratoriais, desta forma, apenas 17 foram selecionados.

Os critérios de avaliação considerados foram: revista em que o trabalho foi publicado; local da pesquisa; tipo de pesquisa (artigo original e relato de caso); família em que se enquadra a espécie do morcego; origem dos animais; características alimentares (hematófagos e não hematófagos); número de amostras, ou seja, a quantidade de morcegos que foram submetidos à análise laboratorial; número de amostras positivas; tipo de material analisado, contendo a descrição do tecido usado para análise; método de diagnóstico, com a descrição dos métodos usados pelos pesquisadores para determinação de positividade das amostras.

\section{Resultados}

Dentre as publicações pesquisadas que atenderam aos critérios de inclusão, foram selecionados 17 artigos que realizaram a captura de morcegos para a análise laboratorial do vírus da raiva. Destas publicações, 13 eram artigos originais e quatro eram relatos de caso (Tabela 1).

Em relação às famílias cujos morcegos se enquadravam aos parâmetros da pesquisa, o mais comum ou o mais observado nas publicações foram os da família Phyllostomidae (12/17, 70.59\%), seguido da família Molossidae (9/17, 52,94\%), família Vespertilionidae $(6 / 17,35,29 \%)$ e por fim 
das famílias Emballorunidae e Noctilionidae que apareceram apenas em uma publicação cada $(5,88 \%)$ (Tabela 2). Não foi possível analisar a presença do vírus em nível de espécie de morcegos, pois a maior parte das pesquisas não apresentavam tais dados, sendo assim, foi feita análise apenas em relação à família.

Os animais utilizados para as pesquisas eram provenientes de vários ambientes, tais como: regiões metropolitanas, áreas rurais, casas habitadas e não habitadas, Universidades, barracões, túneis, pontes e bueiros, porém, partes dessas pesquisas utilizaram como fonte das amostras, institutos responsáveis por fazerem o recolhimento e identificação dos animais assim como a análise laboratorial de doenças virais (Tabela 2).

As características alimentares dos morcegos coletados variaram entre hematófagos (9/17, $52,94 \%$ ), os que se alimentam de sangue, e os não hematófagos $(14 / 17,82,35 \%)$, representados pelos morcegos insetívoros, frugívoros e nectarívoros (Tabela 2).

Dentre os morcegos hematófagos a espécie Desmodus rotundus foi a única descrita entre os mamíferos observados, porém nas publicações de Teixeira et al. (2008) e Queiroz et al. (2009) não foram descritas as espécies de morcegos que foram analisadas, assim, no presente trabalho foi limitada a descrição de hábitos alimentares como hematófagos e não-hematófagos.
O número de amostras ao longo do período de 2007 a 2017 foi de 18.248 morcegos analisados, dos quais $504(2,76 \%)$ foram diagnosticados positivos para o vírus da raiva (Tabela 3 ).

As amostras submetidas às análises laboratoriais foram retiradas de diversos tecidos, sendo que a maior parte deles foi originada do tecido cerebral do morcego (13/17, 76,47\%), seguido de sangue, língua, coração, rim e pulmão que foram utilizados apenas em duas pesquisas (Scheffer et al., 2007; Vieira et al., 2011). Em apenas um experimento foram colhidas amostras da glândula salivar, bexiga urinária, gordura interescapular, trato genital, estômago e músculo peitoral (Scheffer et al., 2007).

Por falta de informações não foi possível determinar o material biológico usado nas análises de quatro publicações (Ferraz et al., 2007; Rosa et al., 2011; Gomes et al.; 2012; Sato et al., 2015).

Em relação ao método de diagnóstico, com exceção de uma publicação (Scheffer et al., 2007), a imunofluorescência direta foi o teste mais usado $(14 / 17,82,35 \%)$ (Tabela 3), seguido da inoculação intracerebral em camundongos (13/17, 76,47\%), sendo o isolamento viral usado em três pesquisas (Scheffer et al., 2007; Vieira et al., 2010; Vieira et al., 2011) enquanto o teste de rápida inibição de focos fluorescentes foi usado em apenas um (Almeida et al., 2011b).

Tabela 1. Artigos selecionados da base de dados da SciELO publicados durante o período de 2007 a 2017 que a partir de amostras teciduais coletadas de morcegos foi possível fazer uma análise de positividade para o vírus da raiva.

\begin{tabular}{|c|c|c|c|c|}
\hline Identificação & Autores & Revista & Local da pesquisa & Tipo de pesquisa \\
\hline 1 & Scheffer et al. (2007) & Revista de Saúde Pública & São Paulo & Artigo original \\
\hline 2 & Ferraz et al. (2007) & Revista do Instituto de Medicina Tropical de São Paulo & Ubatuba, SP & Relato de caso \\
\hline 3 & Teixeira et al. (2008) & Pesquisa Veterinária Brasileira & Rio Grande do Sul & Artigo original \\
\hline 4 & Albas et al. (2009) & Revista da Sociedade Brasileira de Medicina Tropical & USP* & Artigo original \\
\hline 5 & Queiroz et al. (2009) & Revista da Sociedade Brasileira de Medicina Tropical & Araçatuba, SP & Artigo original \\
\hline 6 & Carneiro et al. (2009) & Revista da Sociedade Brasileira de Medicina Tropical & Monte Carlos, MG & Relato de caso \\
\hline 7 & Vieira et al. (2010) & Arquivo Brasileiro de Medicina Veterinária e Zootecnia & RJ e ES & Artigo original \\
\hline 8 & Almeida et al. (2011) & Revista do Instituto de Medicina Tropical de São Paulo & Jundiaí, SP & Artigo original \\
\hline 9 & Almeida et al. (2011) & Revista da Sociedade Brasileira de Medicina Tropical & São Paulo & Artigo original \\
\hline 10 & Avelino et al. (2011) & Revista da Sociedade Brasileira de Medicina Tropical & Presidente Prudente, SP & Artigo Original \\
\hline 11 & Rosa et al. (2011) & Revista da Sociedade Brasileira de Medicina Tropical & São Paulo capital & Relato de Caso \\
\hline 12 & Silva et al. (2011) & Revista da Sociedade Brasileira de Medicina Tropical & Recife, PE & Relato de caso \\
\hline 13 & Vieira et al. (2011) & Pesquisa Veterinária Brasileira & Quissamã, RJ & Artigo original \\
\hline 14 & Cabral et al. (2012) & Revista da Sociedade Brasileira de Medicina Tropical & Rio de Janeiro & Artigo original \\
\hline 15 & Gomes et al. (2012) & Arquivos do Instituto Biológico & Paraíba & Artigo original \\
\hline 16 & Sato et al. (2015) & Papéis Avulsos de Zoologia & Itirapina, SP & Artigo original \\
\hline 17 & Oliveira et al. (2015) & Revista do Instituto de Medicina Tropical de São Paulo & Capanema, Pará & Artigo original \\
\hline
\end{tabular}

* Instituto de Ciências Biomédicas da Universidade de São Paulo. 
Tabela 2. Determinação da família e origem dos morcegos assim como seu hábito alimentar.

\begin{tabular}{|c|c|c|c|}
\hline $\begin{array}{l}\text { Identificação } \\
\text { do artigo }\end{array}$ & $\begin{array}{c}\text { Família do } \\
\text { morcego }\end{array}$ & Origem dos animais & Característica \\
\hline 1 & $2,4,5$ & Municípios do estado de São Paulo ou Instituto Pasteur de São Paulo & Não hematófago e hematófago \\
\hline 2 & 2 & Residência na área urbana de Ubatuba & Hematófago \\
\hline 3 & --- & $\begin{array}{l}\text { Instituto de Pesquisas Veterinárias Desidério Finamor, no Estado do } \\
\text { Rio Grande do Sul, Brasil. }\end{array}$ & --- \\
\hline 4 & $2,4,5$ & Região de Presidente Prudente, São Paulo & Não hematófago \\
\hline 5 & --- & $\begin{array}{l}\text { Diagnóstico de Raiva da UNESP e Laboratório da Unidade de } \\
\text { Pesquisa e Desenvolvimento do PRDTA Extremo Oeste/APTA }\end{array}$ & Não hematófago e hematófago \\
\hline 6 & 2 & Residências de Monte Carlos & Não hematófago \\
\hline 7 & 2 & Abrigos naturais e artificiais & Hematófago \\
\hline 8 & 5 & Sótão de uma casa & Não hematófago \\
\hline 9 & $1,2,4$ & Capanema, Pará & Não hematófago \\
\hline 10 & $2,3,4,5$ & Barracão, túnel, ponte, casas, bueiros. & Não hematófago \\
\hline 11 & 2,4 & Casas e apartamento & Não hematófago \\
\hline 12 & 4 & Recife & Não hematófago \\
\hline 13 & 2 & Abrigo em Quissamã, Rio de Janeiro & Hematófago \\
\hline 14 & 2,4 & $\begin{array}{l}\text { Seção de Virologia do Instituto Municipal de Medicina Veterinária } \\
\text { Jorge Vaitsman, Rio de Janeiro }\end{array}$ & Não hematófago \\
\hline 15 & 4 & $\begin{array}{l}\text { Centro de Saúde e Tecnologia Rural, Universidade Federal de Campina } \\
\text { Grande (CSTR/UFCG), Patos, Paraíba. }\end{array}$ & Não hematófago \\
\hline 16 & 2,5 & Estação Experimental de Itirapina & Não hematófago e hematófago \\
\hline 17 & $2,4,5$ & Cidades do estado de São Paulo & Não hematófago \\
\hline
\end{tabular}

Tabela 3. Número total de morcegos analisados e sua positividade para o vírus da raiva.

\begin{tabular}{|c|c|c|c|c|}
\hline $\begin{array}{l}\text { Identificação do } \\
\text { artigo }\end{array}$ & $\begin{array}{c}\text { Número de amostras } \\
\text { colhidas }\end{array}$ & $\begin{array}{c}\text { Número de amostras } \\
\text { positivas }\end{array}$ & Tipo de material analisado & Método de diagnóstico \\
\hline 1 & 4.393 & $82(1,87 \%)$ & $\begin{array}{l}\text { Cérebro, Glândula salivar, língua, } \\
\text { bexiga urinária, coração, pulmão, } \\
\text { gordura interescapular, rim, trato } \\
\text { genital, estomago, musculo peitoral }\end{array}$ & 2,3 \\
\hline 2 & 1 & $1(100,00 \%)$ & --- & 1,3 \\
\hline 3 & 1.768 & $29(1,64 \%)$ & Cérebro & 1,2 \\
\hline 4 & 18 & $18(100,00 \%)$ & Cérebro & 1,2 \\
\hline 5 & 4.035 & $50(1,23 \%)$ & Cérebro & 1,2 \\
\hline 6 & 2 & $2(100,00 \%)$ & Cérebro & 1,2 \\
\hline 7 & 199 & $7(3,51 \%)$ & Cérebro & 1,3 \\
\hline 8 & 122 & $6(4,92 \%)$ & Cérebro & 1,2 \\
\hline 9 & 441 & $222(50,34 \%)$ & Sangue e cérebro & $1,2,4$ \\
\hline 10 & 1.113 & $11(0,99 \%)$ & Cérebro & 1,2 \\
\hline 11 & 3 & $3(100,00 \%)$ & --- & 1,2 \\
\hline 12 & 4 & $4(100,00 \%)$ & Cérebro & 1,2 \\
\hline 13 & 14 & $5(35,71 \%)$ & $\begin{array}{l}\text { Cérebro, língua, coração, rim, } \\
\text { pulmão e fígado. }\end{array}$ & 1,3 \\
\hline 14 & 198 & $11(5,56 \%)$ & Cérebro & 1 \\
\hline 15 & 200 & $9(4,5 \%)$ & --- & 1,2 \\
\hline 16 & 67 & $0(0,00 \%)$ & --- & 1,2 \\
\hline 17 & 5.670 & $44(0,78 \%)$ & Sangue e cérebro & 1,2 \\
\hline TOTAL & 18.248 & $504(2,76 \%)$ & --- & --- \\
\hline
\end{tabular}

Método de teste: 1=Teste de Imunofluorescência direta; 2= Inoculação intracerebral em camundongos; 3= Isolamento viral; 4= Teste de Rápida Inibição de Focos Fluorescentes

\section{Discussão}

Segundo conhecimento popular, os morcegos estão amplamente ligados à disseminação do vírus da raiva, o que geralmente está ligado ao fato de que alguns deles, no caso os hematófagos, se alimentem de sangue. Contudo, esta afirmação carece de maiores conhecimentos visto que, apenas três espécies de morcegos apresentam este hábito alimentar, além disso dentro do período de 10 anos a maior parte dos morcegos que apresentaram positividade para a raiva neste trabalho foram espécies de hábitos frugívoros e insetívoros (Tabela 2).

Os morcegos hematófagos que foram descritos no presente trabalho são unicamente os da espécie $D$. rotundus, relatos deste morcego ligados a casos em que bovinos apresentavam pequenos cortes sugerem que servem como fonte de alimentação por meio de lambedura (Greenhall et al., 1971).

Raramente os morcegos hematófagos interagem ou se alimentam do sangue humano, que 
por sua vez é substituído pelo sangue de aves, e de mamíferos não humanos (Aguiar e Camargo, 2007; Breidenstein, 2010).

Mendes et al. (2009) relataram um surto de raiva, em humanos, causado em maior parte por morcegos da espécie D. rotundus em uma cidade do interior da Amazônia, onde dos 57 casos encontrados, houve 16 óbitos.

No presente trabalho, os morcegos não hematófagos foram descritos em 14 trabalhos $(82,35 \%)$ (Tabela 2). Dentre eles, a maior parte foi da família Phyllostomidae e Molossidae (Tabela 2). Segundo Albas et al. (2009), morcegos não hematófagos também apresentam potencial transmissor do vírus rábico, visto que este ocasionalmente entra em contato com morcegos carreadores do vírus e posteriormente fazem a disseminação do patógeno por meio do contato direto com animais domésticos e pessoas.

De acordo com Barros et al. (2006) a presença de morcegos de origem silvestre em áreas urbanas decorre da fragmentação florestal e a perda de refúgios que forçam estes animais a adentrarem em residências onde posteriormente formam colônias. Desta forma, é possível dizer que o contato indireto entre morcegos silvestres e o homem se torna mais comum, tornando um assunto de grande preocupação entre áreas rurais e urbanas.

Esses morcegos não hematófagos apresentam grande importância em meio ecológico, sendo que os insetívoros fazem o controle de pragas, podendo consumir uma grande quantidade de insetos durante a noite e os morcegos frugívoros ao se alimentarem fazem a dispersão de sementes ao longo da noite (Boyles et al., 2011). Segundo Albuquerque et al. (2016) os morcegos exibem um comportamento social peculiar, onde estes formam colônias mistas e interagem uns com os outros diretamente.

Lyssavirus é um vírus que após infectar o hospedeiro pode ser observado na maior parte de seus órgãos, porém, o mais afetado é o cérebro, sendo que os sintomas em humanos estão relacionados com disfunção cerebral, seguido de agitação que posteriormente pode causar comportamentos anormais, delírios e demência e em casos mais graves, a deficiência cognitiva gera o coma, a fase aguda da doença pode durar de dois a 10 dias o que na maior parte das vezes resulta no óbito do indivíduo afetado (Calisher e Ellison, 2012).

Em relação aos métodos de diagnóstico, apenas um dos trabalhos não apresentou o teste de imunofluorescência direta (TID) como parte da detecção do Lyssavirus (Scheffer et al., 2007), porém, o mesmo foi o mais completo em relação a amostras provenientes de órgãos diferentes. Portanto, o TID pode ser considerado o método mais confiável para a detecção do vírus, sendo ele complementado em 12 casos $(70,59 \%)$ pela inoculação intracerebral em camundongos (Tabela $3)$.

Os órgãos irrigados com sangue infectado podem apresentar o vírus da raiva em quantidades diferentes, sendo assim o diagnóstico necessita ser obtido a partir da análise dos órgãos mais afetados, tais como o cérebro (por apresentar as maiores disfunções causadas pelo vírus) e o sangue (por garantir a circulação do vírus) assim como no trabalho apresentado por Scheffer et al. (2007).

Após a análise dos trabalhos não foi possível determinar geograficamente a maior área de concentração das amostras positivas, visto que estas foram provenientes de locais diversos onde os autores muitas vezes não realizaram a sua descrição. Isso pode estar relacionado ao fato de que parte das amostras foram encaminhadas de locais não relatados a centros de pesquisa, assim como o Laboratório da Unidade de Pesquisa e Desenvolvimento do Polo Regional de Desenvolvimento Tecnológico dos Agronegócios (PRDTA) do Instituto de Pesquisas Veterinárias Desidério Finamor, no Estado do Rio Grande do Sul (Teixeira et al., 2008; Queiroz et al., 2009).

Segundo a literatura os quirópteros podem apresentar grande diversidade de doenças, sendo então considerados reservatórios naturais das mesmas. No entanto, salienta-se ainda que o fato deles suportarem essas doenças sem danos visíveis está diretamente ligado à sua alta temperatura corporal, diversidade alimentar, períodos de torpor diário e suas características de hibernação (Calisher et al., 2006; Kotait et al., 2007).

Por outro lado, os danos causados pelo vírus rábico em animais de criação e humanos é muito mais visível e perigoso, desta forma é importante que os animais de criação sejam devidamente vacinados assim como os humanos, em casos mais graves deve-se seguir o protocolo de tratamento de raiva previsto pelo Ministério da Saúde (BRASIL, 2009).

\section{Conclusão}

A partir dos trabalhos analisados é possível determinar que as amostras positivas para o vírus rábico no período de 2007-2017 de acordo com a 
base de dados SciELO foram baixas (2,76\%), com predomínio para morcegos não hematófagos, sendo que as principais amostras obtidas para isolamento foram sangue e fragmentos do cérebro, com predomínio para o teste de imunofluorescência direta e a inoculação intracerebral em camundongos.

Também é possível determinar que, apenas dentro dos parâmetros de pesquisa, se faz necessário maiores estudos sobre a relação dos morcegos hematófagos e principalmente não hematófagos com a dispersão do vírus rábico, assim como ressaltar suas formas de profilaxia e de tratamento.

\section{Conflito de Interesse}

Os autores declaram não existir conflito de interesse.

\section{Referências}

Aguiar, L.M.S.; Camargo, W.R. Dados biológicos do morcego-vampiro Diaemus youngi no Cerrado do Distrito Federal, Brasil. Planaltina, DF: Embrapa Cerrados, Boletim de Pesquisa e Desenvolvimento, 178, 2007. 16 p.

Albas, A.; Souza, E.A.N.; Lourenço, R.A.; Favoretto, S.R.; Sodré, M.M. Perfil antigênico do vírus da raiva isolado de diferentes espécies de morcegos não hematófagos da Região de Presidente Prudente, Estado de São Paulo. Revista da Sociedade Brasileira de Medicina Tropical, 42(1): 15-17, 2009.

Albuquerque, A.C; Moraes, M.F.; Silva, A.C.; Lapera, I.M.; Tebaldi, J.H.; Lux Hoppe, E.G. Helminth fauna of chiropterans in Amazonia: biological interactions between parasite and host. Parasitology Research, 115(8): 3229-3237, 2016.

Almeida, M.F.; Martorelli, L.F.A.; Sodré, M.M.; Kataoka, A.P.A.G.; Rosa, A.R.; Oliveira, M.L.; Amatuzzi, E. Rabies diagnosis and serology in bats from the State of Sao Paulo, Brazil. Revista da Sociedade Brasileira de Medicina Tropical, 44(2): 140-145, 2011a.

Almeida, M.F.; Favoretto, S.R.; Martorelli, L.F.A.; Trezza-Netto, J.; Campos, A.C.A.; Ozahata, C.H. Caracterização do vírus da raiva isolado de uma colônia de morcegos Eptesicus furinalis, do Brasil. Revista do Instituto de Medicina Tropical São Paulo, 53(1): 31-37, 2011b.

Arruda, R.C.N.; Barçante, T.A.; Peconick, A.P.;
Pereira, S.M.; Souza, J.C.P.; Sousa, T.M.; Barçante, J.M.P. Captura de Desmodus rotundus em regiões de mata e manguezais do Estado do Maranhão : um estudo longitudinal. Pesquisa Veterinária Brasileira, 33(5): 571574, 2013.

Barros, R.S.M.; Bisaggio, E.L.; Borges, R.C. Morcegos (mammalia, chiroptera) em fragmentos florestais urbanos no município de Juiz de Fora, Minas Gerais, Sudeste do Brasil. Biotropica, 6(1): 1-6, 2006.

Boyles, J.G.; Cryan, P.M.; McCracken, G.F.; Kunz, T.H. Economic Importance of Bats in Agriculture. Science, 332(6025): 41-42, 2011. Breidenstein, C.P. Digestion and Assimilation of Bovine Blood by a Vampire Bat (Desmodus rotundus). American Society of Mammalogists, 63(3): 482-484, 2010.

Cabral, C.C., Morais, A.C.N.D., Dias, A.V.D.A.B., Araújo, M.G., Moreira, W.C.; Mattos, G.L.M. Circulation of the rabies virus in nonhematophagous bats in the city of Rio de Janeiro, Brazil, during 2001-2010. Revista da Sociedade Brasileira de Medicina Tropical, 45(2): 180-183, 2012.

Calisher, C.H.; Childs, J.E.; Field, H.E.; Holmes, K.V.; Schountz, T. Bats: Important Reservoir Hosts of Emerging Viruses. Clinical Microbiology Reviews, 19(3): 531-545, 2006.

Calisher, C.H.; Ellison, J.A. The other rabies viruses: The emergence and importance of lyssaviruses from bats and other vertebrates. Travel Medicine and Infectious Disease, 10(2): 69-79, 2012.

Carneiro, N.F.D.F.; Caldeira, A.P.; Antunes, L.A.; Carneiro, V.F.; Carneiro, G.F. Rabies in Artibeus lituratus bats in Montes Claros, State of Minas Gerais. Revista da Sociedade Brasileira de Medicina Tropical, 42(4): 449-451, 2009.

Departamento de Vigilância Epidemiológica. Protocolo para tratamento de raiva humana no Brasil. Revista Epidemiologia e Serviços de Saúde, 18(4): 385-394, 2009.

Ferraz, C.; Achkar, S.M.; Kotait, I. First report of rabies in vampire bats (Desmodus rotundus) in an urban area, Ubatuba, São Paulo State, Brazil. Revista do Instituto de Medicina Tropical de São Paulo, 49(6): 389-390, 2007.

Flores, E. F. Virologia veterinária. Santa Maria: UFSM, 2007. 888p. 
Gomes, A.A.B.; Silva, M.L.C.R.; Bernardi, F.; Sakai, T.; Itou, T.; Ito, F.H. Molecular epidemiology of animal rabies in the semiarid region of Paraíba, Northeastern Brazil. Arquivos do Instituto Biológico, 79(4): 611615, 2012.

Greenhall, A.M.; Schmidt, U.; Lopez-Forment, W. Attacking Behavior of the Vampire Bat, Desmodus rotundus, Under Field Conditions in Mexico. Biotropica, 3(2): 136-141, 1971.

Johnson, N.; Vos, A.; Freuling, C.; Tordo, N.; Fooks, A.R.; Müller, T. Human rabies due to lyssavirus infection of bat origin. Veterinary Microbiology, 142(3): 151-159, 2010.

Kotait, I.; Carrieri, M.L.; Carnieli Júnior, P.; Castilho, J.G.; Oliveira, R.D.N.; Macedo, C.I.; Ferreira, K.C.S.; Achkar, S.M. Reservatórios silvestres do vírus da raiva: um desafio para a saúde pública. Boletim Epidemiológico Paulista, 4(40): 2-8, 2007.

Lima, F.G.; Gagliani, L.H. Raiva: aspectos epidemiológicos, controle e diagnóstico laboratorial. UNILUS Ensino e Pesquisa, 11(13): 45-62, 2014.

Macias-Chapula, C.A. O papel da informetria e da cienciometria e sua perspectiva nacional e internacional. Ciência da Informação, 27(2): 134-140, 1998.

Mendes, W.D.S.; Silva, A.A.M.D.; Neiva, R.F.; Costa, N.M.; Assis, M.S.D.; Vidigal, P.M.O.; Branco, M.R.F.C.; Leite, M.G.L.; Rios, J.M.T.; Martins, J.O.S.; Waquin Neto, S.J. An outbreak of bat-transmitted human rabies in a village in the Brazilian Amazon. Revista de Saúde Pública, 43(6): 1075-1077, 2009.

Núñez, C.; Páez, A.; Hernández, C.; Escobar, H.; Bonelo, A. Transmisión del virus de la rabia entre murciélagos urbanos del departamento del Valle del Cauca, Colombia, 1999-2008. Infectio: revista de la Asociación Colombiana de Infectología, 16(1): 23-29, 2012.

Oliveira, R.S.D., Costa, L.J.C.D., Andrade, F.A.G.D., Uieda, W., Martorelli, L.F.A., Kataoka, A.P.D.A.G.; Rosa, E.S.T.; Vasconcelos, P.F.C.; Pereira, A.S.; Carmo, A.I.B.; Fernandes, M.E.B. Virological and serological diagnosis of rabies in bats from an urban area in the brazilian Amazon. Revista do Instituto de Medicina Tropical de São Paulo, 57(6): 497-503, 2015.

Queiroz, L.H.; Carvalho, C.D.; Buso, D.S.; Ferrari,
C.I.D.L.; Pedro, W.A. Epidemiological profile of rabies in the northwestern region of São Paulo State, from 1993 to 2007. Revista da Sociedade Brasileira de Medicina Tropical, 42(1): 9-14, 2009.

Rosa, A.R.D.; Kataoka, A.P.D.A.G.; Favoretto, S.R.; Sodré, M.M.; Trezza Netto, J.; Campos, A.C.D.A.; Durigon, E.L.; Martorelli, L.F.A. First report of rabies infection in bats, Molossus, Molossops neglectus and Myotis riparius in the city of São Paulo, state of São Paulo, Southeastern Brazil. Revista da Sociedade Brasileira de Medicina Tropical, 44(2): 146-149, 2011.

Samson, M.; Pizzorno, A.; Abed, Y.; Boivin, G. Influenza virus resistance to neuraminidase inhibitors. Antiviral Research, 98(2): 174185, 2013.

Sato, T.M.; Carvalho-Ricardo, M.C.D.; Uieda, W.; Passos, F.C. estrutura da comunidade de morcegos (Mammalia, Chiroptera) da estação experimental de Itirapina, estado de São Paulo, Brasil. Papéis Avulsos de Zoologia, São Paulo, 55(1): 1-11, 2015.

Scheffer, K. C.; Carrieri, M.L.; Albas, A.; Dos Santos, H.C.P.; Kotait, I.; Ito, F.H. Virus da raiva em quiropteros naturalmente infectados no Estado de São Paulo, Brasil. Revista de Saúde Pública, 41(3): 389-395, 2007.

Silva, L.A.M.D.; Machado, J.L.M.; Melo, M.D.L.; Alencar, V.I.D.B.; Melo, R.S.D.; Andrade, L.P.D.; Silva, E.M.V.G.D. Rabies virus in Molossus molossus (Chiroptera: Molossidae) in the State of Pernambuco, Northeastern Brazil. Revista da Sociedade Brasileira de Medicina Tropical, 44(4): 526-527, 2011.

Teixeira, T.F.; Holz, C.L.; Caixeta, S.P.; Dezen, D.; Cibulski, S.P.; da Silva, J.R.; Rosa, J.C.A.; Schmidt, E.; Ferreira, J.C.; Batista, H.B.C.R.; Caldas, E.; Franco, A.C.; Roehe, P.M. Diagnóstico de raiva no Rio Grande do Sul, Brasil, de 1985 a 2007. Pesquisa Veterinária Brasileira, 28(10): 515-520, 2008.

Tiriba, A. C.; Shmal, M. R. Morcegos na área urbana: doença adquirida na moradia. Diagnóstico e Tratamento, 15(2): 61-63, 2010.

Vanti, N.A.P. La bibliometría y webmetría: una exploración conceptual de mecanismos utilizados para medir registro de información y la difusión del conocimiento. Ciência da Informação, 31(2): 152-162, 2002.

Vieira, L.F.P.; Pereira, S.R.F.G.; Brandão, P.E.; 
Oliveira, R.N.; Carnieli-Junior, P.; Galante, A.C.; Chicarino, C.N.; Kotait, I. Molecular characterization of rabies virus isolated from Desmodus rotundus captured in Rio de Janeiro State. Arquivo Brasileiro de Medicina Veterinária e Zootecnia, 62(2): 343-349, 2010.

Vieira, L.F.; Pereira, S.R.; Galante, A.C.; Castilho, J.G.; Oliveira, R.N.; Brandão, P.E.; Kotait, I. Detection of rabies virus nucleoprotein-
RNA in several organs outside the Central Nervous System in naturally-infected vampire bats. Pesquisa Veterinária Brasileira, 31(10): 922, 2011.

Kuzmin, I.V.; Rupprecht, C. E. Bats Lyssaviruses. In: Wang, L. F.; Cowled, C. Bats and viruses: A new frontier of emerging infectious diseases. $1^{\text {st }}$ ed. New Jersey: WileyBlackwell, 2015. p. 47-98. 